\title{
Is Language Proficiency Taken Care of at Higher Education Level? Need for Self Efficacy of Post Graduate Students
}

\author{
H. Jeraltin Vency \\ Department of Educational Technology, Bharathidasan University, Tiruchirappalli, India \\ E. Ramganesh \\ Department of Educational Technology, Bharathidasan University, Tiruchirappalli, India
}

\begin{abstract}
English language is known for its global communication. As a link language and the migration of people from different parts of the world to various places, for pursuing their higher education, trade contacts and better living (Saraithong \& Chancharoenchai, 2012) a proficiency in this language has received a paramount importance. ICT also demands the knowledge of this language as most of the resources are in this English language. Spoken English classes are more prominent in India among young people who are in their verge of job hunt. But huge sum of money are bagged by these proprietors of these classes without, any change in the pupil's ability. A proper teaching methodology along with appropriate curriculum introduced from the primary level to the tertiary level in education can fill these gaps of expectations and swindle. At this backdrop the investigators underwent this study of finding the language proficiency of post graduate students the results of which can be used for revision of curriculum, teaching methodology, identifying grey areas in the education system on the whole, so that every stakeholder can witness their goals and objectives being achieved. A written inventory comprising of 15 situational tasks was developed by the investigators and administered in two colleges for 64 participants. The responses were scored using analytical rubrics and statistically analyzed. The results convey the need for in depth revision in sowing the skills of English language among college students in a vigorous manner, so that the students grow and glow in the English language dominant world.
\end{abstract}

Index Terms-performance based assessments, pragmatic approach and sub skills of LSRW in English Language

\section{RATIONALE FOR THE STUDY}

English language proficiency a magical word rules the young minds of this technological era. Everyone likes to be proficient in this language for want of better living, to study abroad, to learn new culture and for trade relationships. Language is the vehicle of thought. English serves as the link language in many parts of the world and globalization had necessitated being proficient in this language. In India people from the daily wagers till the millionaire wanted their children to have English education and expect them to be fluent in this language A survey states that India has a moderate proficiency in English with $57.49 \%$ (EF -EPI, 2012). The ethnocentrism for a particular language may be one reason but when English had been accepted as an official language steps are taken by the government to bring English education to its mass population. The extensive review of literature done by the investigators provided guidelines for the administration of the present study right from the fixing of objectives to picking up of test items, its validation, preparation of rubrics, scoring and analysis of the test results. The objectives of the present study are to assess the English Language Proficiency of post graduate students by analyzing the sub skills of major LSRW skills and its relation to demographic variables.

In the Guidelines for the assessment of the English Language Learners given by Educational Testing Services U.S (Pitoniak, Young, Martiniello, King, Buteux, et,al, 2009) states that the factors that affect assessment of English Language learners are Different linguistic backgrounds, Varying levels of proficiency in English, Varying levels of proficiency in native language, Varying degrees of formal schooling in native language etc. National Curriculum Statement Assessment Guidelines for General Education and Training (Intermediate and Senior Phases) Languages (2007) given by the Department of Education, Republic of South Africa ensures that "The content for Languages is dependent upon other learning areas' content. Language teachers need to take into consideration that there would always be Learning Outcomes that are content specific for other Learning Areas such as Life Orientation, Social Sciences, Arts and Culture, Technology, etc. The work English as a Second Language Learners: ESL Learners: A Guide for Classroom Teachers (1999) British Columbia Ministry of Education Special Programs Branch induces the need for proper scoring stating that "The proper scoring of ELLs' responses includes an understanding of the language or presentation style examinees use". Also the study explains that "Informal assessment techniques can be used at anytime without interfering with instructional time. Their results are indicative of the student's performance on the skill 
or subject of interest" and "Methods for informal assessment can be divided into two main types: unstructured (e.g., student work samples, journals) and structured (e.g., checklists, observations). The unstructured methods frequently are somewhat more difficult to score and evaluate, but they can provide a great deal of valuable information about the skills of the students, particularly in the areas of language proficiency." "The validity of informal measures can be established by demonstrating that the information obtained from a given technique reflects the project's instructional goals and objectives."

Anne \& Heidi (1990) in their study “Oral Skills Testing: A Rhetorical Task Approach" have used a semi direct test of oral proficiency named the Rhetorical Task Examination (RTE). In their study they used performance based tasks involving short questions and answers, description, narration, process (giving directions), opinion, and comparisoncontrast. The same method is adapted in the present study. Results of this study indicate that the Rhetorical Task Examination is promising as a measure of oral proficiency in terms of practicality, reliability, and validity. Ramganesh \& Pandiyan (2009) in his study states that cognitive strategy is one of the six strategies used by the readers and that they analyze, and summarize using context cues, so providing a task based activity is cognitively demanding the target language use by the learner, which adds to the advantage in the use of these task based activities in this study. As given in the study by Tanveer (2007) anxiety forms an obstacle for second language communication. The result of his study is that "Anxiety and speech communication appear to have a strong bond with each other. Speaking, either in first (L1) or second/foreign (L2/FL) language in different situations, particularly the situations that demand public speech, tend to be anxiety provoking". Pearson, KT has automatically scored many millions of written and spoken responses. KT has measured core language and literacy skills as evidenced in students' constructed responses. Similar tasks also elicit responses that are assessed for content knowledge. Pearson knowledge technologies group assessed as follows. The items measure language production, written and oral skills, pronunciation, and fluency among other language traits. NCME Instructional Module on Design and 'Development of Performance Assessments by Stiggins (1987) supports that Performance assessments are valuable tools for measuring communication skills such as reading, writing, speaking, and listening. In a study by Çetin and Demiral (2012) the investigators report that 'The evaluation results can give guidance in terms of identifying the students' development levels, needs and appropriate learning activities to them and editing the learning environment. Abedi (2004) had stated some language assessment tests; they are the Bilingual Syntax Measure (BSM), the Idea Proficiency Test (IPT), the Language Assessment Battery (LAB), the Language Assessment Scales (LAS), the Maculaitis Assessment Program (MAC), and the Peabody Picture Vocabulary Test (PPVT).

Every institution has its own way of language assessment for entry into their college or for job in a company. The most popularly known test is the TOEFL and TOEIC. The TOEFL $®$ test, is a test which colleges and universities use to gauge the language skills of prospective international students, and the TOEIC® test, is a test in which employers in a variety of industries use to determine employees' readiness to use English in global communication. Language proficiency contributes to academic success too as it is stated by Krashen \& Brown (2007) "Those who read more do better on all aspects of academic language: They have larger vocabularies, spell better, read better, have a more acceptable writing style, and are more adept at handling complex grammatical constructions". The investigators also stated that that the successful students had mastered the real strategies for language development and problem-solving, and did not need strategies for "study."

Language Proficiency is impinged on all the four skills of the language learning. Powers .E (2010) comply that although the four aspects of communicative ability are highly related, they are nonetheless logically and empirically distinct. He also says assessing only some aspects of language proficiency leads to serious societal consequence. English language proficiency assessed in the present study was designed such that it includes the pragmatic dimension of the language and all the four skills were provided with the situational contexts in an inventory comprising of 15 questions. Vecchio and Guerrero (1995) had stated that "Pragmatic language tasks are intended to be as "real life" or authentic as possible". In the inventory the sub skills of each of the main skills namely the LSRW skills were provided with an open end inventory. Since open ended questions provide an opportunity for the sample to give explicit responses and at the same time the tool was to per se the language competence of the sample the investigators found that the open ended questions are more suitable for the present study. Two colleges were used for the study both being private aided coeducation colleges one situated at the urban area and the other on a remote rural area coming under the jurisdiction of Bharathidasan University. Post graduate students of English Literature were used for the study as the students of English literature they are supposed to be equipped with the LSRW skills than the students of any other discipline. College ' $\mathrm{A}$ ' is referred as the college in the rural area and College ' $\mathrm{B}$ ' is referred as the college in the urban area.

\section{SAMPLES}

The investigators adopted purposive sampling in the present study as the objectives of the study imply the comparison between rural and urban college. Two colleges were selected for the study. Post graduate students of English Literature formed the sample. College A consisted of 10 male students and 21 female students and College B 8 male students and 25 female students and both the colleges are private aided colleges with the status of "College with Potential" recognized by University Grants Commission of India. 


\section{LANGUAGE PROFICIENCY INVENTORY}

In the study all the four skills are assessed for it gives a holistic view of the language proficiency. Performance based assessment was adopted in the study as they can be used to evaluate students speaking and writing ability (Abedi, 2010). The CRESST report (Kim, Joan, Lyle, Alison \&Noelle 2008) has given guidelines that the data collection should contain details of native language, mobility, socioeconomic status, instructional history which is incorporated in the study. The inventory consist of two parts namely part I and part II. The part I consist of the general information of the participant like name, gender along with demographic variables such as medium of instruction at primary, secondary and higher secondary level, residential area and economic status. The second part II consisted of 15 open ended questions. Simple statements were used for it affects the response of the participants (Cawthon. W, 2010). The oral discourse skill was assessed with a help of real life situations in the written form. Though there are two forms of discourse skills both oral and written form due to constraints of time, practicality and feasibility the investigators decided to collect written forms of responses in assessing the oral skill of the participants. The oral discourse skill's sub skills such as beginning a conversation with a stranger, self introduction in a seminar presentation, giving compliments, seeking permission and giving directions to stakeholder were administered in the study. Each of the dimensions was given with a situation and the responses were recorded by the participants in the inventory. Five items were included in the study for this particular skill.

The next 5 items were used to assess the writing skill of the participants. The dimensions included exercises in guided writing, descriptive writing, expository writing and note making and one task involves both reading and writing tasks that brings about the skill of transcoding information into a diagrammatic display. But the test item was used for writing skill assessment only. The inventory had 3 items in reading task which includes the dimensions of skimming, guessing meaning from the context and understanding of the content. As the whole of the inventory also assesses the reading skill of the participants the investigators restricted the tasks in reading. Then the inventory comprised of 2 tasks in listening. The investigators read aloud the passages to the participants only once followed by 5 questions from each of the passage. Only the basic understanding of the content was tested in the listening comprehension and the responses were written by the participants in the inventory. A time of about one hour fifteen minutes was given to the participants to complete the inventory along with the brief introduction of the purpose of the research by the investigators and thereby they created a rapport with the participants to bring them out of their shelves.

\section{SCORING Procedure}

Analytical rubrics were taken by the investigators for the scoring of the responses. For the oral discourse skill and the written skill assessment, the scoring was categorized under the use of vocabulary, presentation skills, understanding of the given content and the relevance of the response to the question. For most of the studies looks language proficiency for grammatical competencies (Esquinca, Yaden \& Rueda, 2005). Both the reading and listening skills had only one correct response and a correct response was given a score. The question which consists of assessing both the reading and the writing task had sub divisions and the appropriate score was given. Thus the scoring was systematized and the responses were carefully assessed by the investigators. Then the scores were categorized in to competency levels (Wille. R May 2006). The results were further categorized in their appropriate proficiency levels as stated in IOWA English Language Development Assessment (I-ELDA). In this test the participants are categorized as such 0.00 to 1.75 as level $1,2.00$ to 2.75 as level 2, 3.00 to 3.75 as level 3 and so on (Pl refer references).

\section{RESULTS}

TABLE 1.

OVERALL MEAN SCORE AND STANDARD DEVIATION OF BOTH THE COLLEGES

\begin{tabular}{|l|l|l|l|l|}
\hline \multirow{2}{*}{ Skills } & College A & STDEV & College B & Mean \\
\cline { 2 - 5 } & Mean & 4.72 & 7.73 & STDEV \\
\hline Speaking & 8.13 & 4.27 & 8.55 & 3.75 \\
\hline Writing & 5.94 & 2.11 & 2.03 & 4.16 \\
\hline Reading & 1.71 & 1.88 & 4.15 & 1.97 \\
\hline Listening & 3.32 & & 1.58 \\
\hline
\end{tabular}

\section{A. Oral Proficiency Skill}

The spoken language according to researches is the most complex skill and it increases the anxiety of the ESL (English as Second Language) students. Since their errors are displayed to others the anxiety level also increases. Good communication the root of any action entails the proper understanding of the situation and responding correspondingly. As already given the pragmatic approach of the inventory with the real life situations were given and the students' responses were analyzed statistically. The standard deviation of college A is 4.72 and college B is 3.75. The mean score of the college A is 8.13 and college B is 7.73 . The mean score shows relatively a high proficiency in oral discourse skill for college A. 


\section{B. Written Skill}

The written skill is considered as one of the most important skills as the higher education students is making use of most of it in their semester exams. This skill requires the proper understanding of the questions asked, relevance of response in highly sequenced manner with varying degree of vocabulary and with a little patience too, to make the reader perceive the meaning as it is interpreted and conveyed by the writer. The standard deviation of college $\mathrm{A}$ is 4.27 and college B is 4.16 the deviation score is almost equal when compared to oral skill for both the colleges. The mean score of college A is 5.94 and college B is 8.55. This shows that compared to oral proficiency college B is good in the written skill and college A is good in oral proficiency than college B.

\section{Reading Skill}

Reading maketh a complete man (Francis Bacon). Only through extensive reading one can extend his knowledge of vocabulary. In this technological era, though reading books is diminishing it should be cultivated in every child's mind at an early stage as this skill also fuels the means of self study. A voracious reader always finds easy to communicate to varied situations and his decision making power also increases. The standard deviation of college $\mathrm{A}$ is found to be 2.11 with the mean score 1.71. The standard deviation of college B is 1.97 with a mean score of 2.03. Transcoding the information into a diagrammatic display gained very low score in the pupils' responses which indicates that this sub skill in reading is to be incorporated in the curriculum of every higher education students as it kindles self study mode among them.

\section{Listening Skill}

Listening is the basic skill for any language development and the most unrecognized skill among the practitioners of education. A child's language development begins with this receptive skill. The factors that affect listening are length of the passage read, environment of the study, use of vocabulary, level of the learners in accordance with the passage and so on. The investigators had control over these factors and the passage was read to the participants by the investigator. Questions asked from the passage include only proper listening of the passage read. The standard deviation of college A and B is 1.88 and 1.58 respectively. The mean score is 3.32 for college A and 4.15 for college B.

TABLE 2

I-ELDA PROFICIENCY LEVELS ASSESSMENT.

\begin{tabular}{|l|l|l|}
\multicolumn{2}{l}{ I-ELDA PROFICIENCY LEVELS ASSESSMENT. } \\
\begin{tabular}{|l|l|l|}
\hline \multicolumn{1}{|c|}{ College A } & College B \\
\hline Skills & Mean & Mean \\
\hline Speaking & 8.13 & 7.73 \\
\hline Writing & 5.94 & 8.55 \\
\hline Reading & 1.71 & 2.03 \\
\hline Listening & 3.32 & 4.15 \\
\hline Mean of all skills & 4.78 & 5.62 \\
\hline
\end{tabular}
\end{tabular}

The mean score of college A and college B falls above 3. This indicates that both the colleges are little proficient in their language.

Level 4 is an advanced intermediate level which indicates that the student who is limited in English proficiency can: (as given by I-ELDA scale)

- Identify some of the main ideas and relevant details of discussions or presentations on a wide range of topics

- Actively engage in most communicative situations familiar to him or her

- Understand the context of most text in academic areas with support

- Write some multi-paragraph essays, journal entries, personal/business letters, and creative texts in an organized fashion with errors

Analysis in relation to demographic variables such as

1. Gender

2. Residential Area

3. Economic status

4. Medium of Instruction (Higher Secondary) 
TABLE 3

GENDER DIFFERENCE

\begin{tabular}{|l|l||c||c||c|c||c|}
\hline \multirow{2}{*}{ SKILLS } & \multicolumn{1}{|c|}{ College A } & Mean & STDEV & College B & Mean & STDEV \\
\hline \multirow{3}{*}{ Speaking } & Male & 7.90 & 3.755 & Male & 7.50 & 1.690 \\
\cline { 2 - 7 } & Female & 8.24 & 5.205 & Female & 7.80 & 4.233 \\
\hline \multirow{3}{*}{ Writing } & Male & 6.10 & 4.654 & Male & 9.13 & 4.673 \\
\cline { 2 - 8 } & Female & 5.86 & 4.199 & Female & 8.36 & 4.081 \\
\hline \multirow{3}{*}{ Reading } & Male & .80 & 1.874 & Male & 1.00 & 1.414 \\
\cline { 2 - 8 } & Female & 2.14 & 2.128 & Female & 2.36 & 2.039 \\
\hline \multirow{2}{*}{ Listening } & Male & 1.90 & 1.287 & Male & 3.50 & .926 \\
\cline { 2 - 8 } & Female & 4.00 & 1.761 & Female & 4.36 & 1.705 \\
\hline
\end{tabular}

The table 3 gives a view of the Mean score and Standard deviation of the participants in relation to the gender difference. Mean score in the male samples of both the colleges show very low score and there is very little difference in the standard deviation and mean score of the reading skill of the male samples. On the whole the performance of the female sample is better than male samples in all the four skills.

TABLE 4

RESIDENTIAL AREA

\begin{tabular}{|l||l||l||l|}
\hline Skills & Residential Area & Mean & Standard Deviation \\
\hline \multirow{5}{*}{ Speaking } & Rural & 7.59 & 4.173 \\
\cline { 2 - 4 } & Urban & 10.50 & 3.398 \\
\cline { 2 - 4 } & Semi Urban & 5.88 & 4.291 \\
\hline \multirow{5}{*}{ Writing } & Rural & 6.34 & 4.182 \\
\hline \multirow{5}{*}{ Reading } & Urban & 9.42 & 3.315 \\
\cline { 2 - 4 } & Semi Urban & 9.25 & 5.548 \\
\hline \multirow{3}{*}{ Listening } & Rural & 1.55 & 1.886 \\
\hline & Urban & 2.25 & 1.815 \\
\hline & Semi Urban & 3.13 & 1.748 \\
\hline & Rural & 3.55 & 1.069 \\
\hline
\end{tabular}

As given in table 4, the mean score of the speaking skill of urban people is little higher than participants belonging to rural and semi urban. More over the mean sore of the writing skill, reading skill and the listening skill shows there is no significant difference among the participants in these skills in relation to residential area. Thus this study confirms that a language rich environment is essential for the speaking skill in particular. As practice makes perfect the enhancement of this speaking skill needs continuous practice. All the other skills are not much affected with the domicile of the participants. 
TABLE 5

ECONOMIC STATUS

\begin{tabular}{|c|c|c|c|}
\hline Skills & Economic Status & Mean & Deviation \\
\hline \multirow{3}{*}{ Speaking } & Lower Middle & 6.20 & 3.427 \\
\hline & Middle & 8.41 & 4.287 \\
\hline & Upper Middle & 9.00 & 6.000 \\
\hline \multirow{3}{*}{ Writing } & Lower Middle & 5.60 & 4.239 \\
\hline & Middle & 7.65 & 4.352 \\
\hline & Upper Middle & 10.00 & 4.359 \\
\hline \multirow{3}{*}{ Reading } & Lower Middle & .73 & 1.223 \\
\hline & Middle & 2.22 & 2.118 \\
\hline & Upper Middle & 2.33 & 2.517 \\
\hline \multirow{3}{*}{ Listening } & Lower Middle & 2.60 & 1.549 \\
\hline & Middle & 4.17 & 1.637 \\
\hline & Upper Middle & 3.00 & 2.646 \\
\hline
\end{tabular}

The mean score given in the above table 5 in relation to economic status shows participants of upper middle class and the middle class are almost equal in the speaking skill and high deviation is seen in the speaking skill of the upper middle class. In the writing skill the standard deviation is almost the same while the mean score is greater for upper middle class. Reading and the Listening skill are poor among all participants with low mean score. The scores on the whole reveal that the economic status does not affect significantly in the English Language Proficiency of the participants.

TABLE 6

MEDIUM OF INSTRUCTION

\begin{tabular}{|l|l||l||l|}
\hline Skills & Higher Secondary & Mean & Standard Deviation \\
\hline \multirow{3}{*}{ Speaking } & Tamil & 6.73 & 4.006 \\
\cline { 2 - 4 } & English & 9.92 & 3.866 \\
\hline \multirow{2}{*}{ Writing } & Tamil & 5.83 & 4.050 \\
\cline { 2 - 4 } & English & 9.71 & 3.884 \\
\hline \multirow{2}{*}{ Reading } & Tamil & 1.65 & 2.007 \\
\cline { 2 - 4 } & English & 2.25 & 2.069 \\
\hline \multirow{2}{*}{ Listening } & Tamil & 3.43 & 1.880 \\
\cline { 2 - 4 } & English & 4.29 & 1.459 \\
\hline
\end{tabular}

Though the medium of instruction at primary, secondary and higher secondary level were taken from the participants for the analysis only the higher secondary level was considered. In all the four skills the English medium students perform better than Tamil medium students. It implies that medium of instruction plays a vital role in the development of language proficiency. This result again confirms the need for early instruction in the second language and the need for language rich environment for language development.

\section{CONCLUSION}

Language proficiency is very much essential for higher education students, as learning a language is learning how to learn through a language. Higher education students are on the brim of finding job. Most of the job offering companies looks for communication skills in English as the most important criteria for the selection of the candidate. Most of the studies say that language proficiency is positively correlated to academic achievement. (Elder, 1994), so concentrating on the language proficiency for language development of the students paves the way for their academic success too. The present study though attempted to assess all the four skills in language development an in depth study by including the grammatical aspects of the language can give a real picture of the students' proficiency level. Language rich environment should be provided from the primary level of school instruction for adequate language development.

The present study explains that the economic status and the area of domicile does not have a major impact on the students language proficiency, probably it may be due to the age factor, in which the self interest and the self study mode may have contributed to the language development of the participants. The study when attempted with other samples including primary and secondary students may yield a different result. This study insists the need to frame a comprehensive curriculum incorporating most of the sub skills of the language right from the primary level and the 
need for inclusion of target language teaching at all levels in the school. Females are good in language proficiency than males and utmost care should be taken for increasing the proficiency of the males too and appropriate teaching strategies are to be developed to reach the male students also. Spoken language when assessed by actually making the participants to speak may give a different result on other hand people whose anxiety level is high (Sioson .C, 2011) and who are with stammering difficulty may not perform well in the test but in actual situations they can do better. Though the LSRW skills are unique, they are interrelated and the development of one skill contributes to the other, and a particular assessment cannot measure one particular skill, such discrepancies should be culled out. Whatever be the exact situation this study adds some knowledge to the present status of the language proficiency prevalent among college students.

\section{REFERENCES}

[1] Abedi Jamal. (2004). English Language Proficiency Assessment in the nation: Current Status and future practice. http://www.cacompcenter.org/downloads/title_iii_elp_report.pdf. (accessed 26/10/2012).

[2] Abedi Jamal. (2010). Performance Assessments for English Language Learners conducted by Stanford Center for Opportunity Policy in Education. http://scale.stanford.edu/system/files/performance-assessments-english-language-learners.pdf (accessed 26/10/2012).

[3] Bailey Alison 1. (CRESST report 727 - 2007). Developing Academic English Language Proficiency Prototypes for 5th Grade Reading: Psychometric And Linguistic Profiles Of Tasks. http://cse.ucla.edu/products/reports/R727.pdf (accessed 25/09/2012).

[4] Cawthon W.Stephanie. (2010). Assessment Accommodations for English Language Learners: The Case of Former-LEPs Volume 15, Number 13, October, 2010. http://pareonline.net/pdf/v15n13.pdf. (accessed 31/10/2012).

[5] Çetin Ayse Yucel \& Demiral Hilmi. (2012 Evaluation of Language and Literature Skills of Secondary School Students in Turkey According to International Baccalaureate Diploma Program, International Journal of Instruction. Volume 5. No.2. http://0-eric.ed.gov.opac.acc.msmc.edu/PDFS/ED533798.pdf (accessed 01/10/2012).

[6] EF English Proficiency Index. http://www ef.com/_/ /media/efcom/epi/2012/full_reports/EF\%20EPI\%202012\%20Report_MASTER_LR pdf (2012). 28/10/2012).

[7] Elder Catherine. (1994). Language Proficiency as Predictor of Performance in Teacher Education. Paper presented at ACTA/VATME Conference, University of Melbourne. http://ltrc.unimelb.edu.au/mplt/papers/02_1_4_Elder.pdf (accessed 26/10/2012).

[8] English as a Second Language Learners: A Guide for Classroom Teachers.

(1999). www.bced.gov.bc.ca/esl/policy/classroom.pdf (accessed 23/09/ 2012).

[9] Esquinca Alberto, Yaden David \& Rueda Robert. (2005). Current Language Proficiency Tests and TheirImplications for Preschool English Language Learners http://www.lingref.com/isb/4/052ISB4.PDF (accessed 17/10/ 2012).

[10] Kim Wolf Mikyung, Herman .I. Joan, Bachman F. Lyle, Bailey. L. Alison \& Griffin Noelle:( JULY, 2008) Recommendations for Assessing English language Learners:English language Proficiency measures and Accommodation uses Recommendations report (Part 3 of 3) http://www.cse.ucla.edu/products/reports/r737.pdf_(accessed 25/10/ 2012).

[11] Krashen Stephen \& Brown Clara Lee. (2007). What is Academic Language Proficiency? http://www.sdkrashen.com/articles/Krashen_Brown_ALP.pdf (accessed 20/10/2012).

[12] LazaratonAnne \&Riggenbach, Heidi. (1990). Oral Skills Testing: A Rhetorical Task Approach Issues in Applied Linguistics, Vol.1 No. 21990 196-217. http://www.escholarship.org/uc/item/77h2z2xh (accessed October 12,201).

[13] National Curriculum Statement Assessment Guidelines for General Education and Training (Intermediate and Senior Phases) Languages. (2007). given by Department of Education Republic of South Africa. http://www.education.gov.za/LinkClick.aspx?fileticket=dfzalH6jGG8\%3D\&....(accessed 8/10/2012).

[14] North West Area Education

http//www.nwaea.k12.ia.us/en/programs_and_services/resear_ pment_assess_i_elda/ (accessed 16/10/2012).

[15] Pitionaik J. Mary, Young. W. John, Martiniello Maria, King. C. Teresa, Buteux Alyssa et al. (2009). Educational Testing Service (ETS) 2009 Guidelines for the Assessment of English Language Learners. http://www.ets.org/s/about/pdf/ell_guidelines.pdf (accessed 10/10/2012).

[16] Powers .E. Donald. (2010). The Case for a Comprehensive, Four Skills Assessment of English Language Proficiency. http://www.ets.org/Media/Research/pdf/TC-10-12.pdf ([accessed 23/10/2012).

[17] Ramganesh.E. \& Pandian S.Raja Soundran. (2009). Efficacy of Metacognition and Reading Comprehension in Higher Education. University News, 47.24, pg 3-6.

[18] [18] Saraithong Wuthiya \& Kanokwan Chancharoen. (2012). The Determinants of New Coming Workers' English Proficiency in the ASEAN Economic Community: A Case of Thai Vocational Students http://www.iises.net/wp-content/uploads/Palermo-papers-Saraitong.pdf. (28/10/ 2012).

[19] Sioson C. Irish. (2011). Language Learning Strategies, Beliefs, and Anxiety in Academic Speaking Task; Philippine ESL Journal, Vol. 7, July 2011.http://www.philippine-esl-journal.com/V7-A1.pdf . (20/10/2012).

[20] Song Xiaomei. (2005). Language Learner Strategy Use and English Proficiency on the Michigan English Language Assessment Battery; Spaan Fellow Working Papers in Second or Foreign Language Assessment, Volume3. http://www.cambridgemichigan.org/sites/default/files/resources/SpaanPapers/Spaan_V3_Song.pdf(accessed 23/10/2012).

[21] Streeter Lyn, Bernstein Jared, Foltz Peter \&Deland Donald (2011). http://www.pearsonassessments.com/hai/images/tmrs/PearsonsAutomatedScoringofWritingSpeakingandMathematics.pdf (accessed 30/09/2012). 
[22] Stiggins J. Richard. (1987). NCME Instructional Module on Design and 'Development of Performance Assessments. http://ncme.org/linkservid/3E3AC538-1320-5CAE-6E780DD57D5D8EE2/showMeta/0/ (accessed 25/10/ 2012).

[23] Tanveer Muhammad. (2007). Investigation of the factors that cause language anxiety for ESL/EFL learners in learning speaking skills and the influence it casts on communication in the target language http://asian-efl-journal.com/thesis_M_Tanveer.pdf (accessed 23/10/2012).

[24] Vecchio Del Ann \&Guerrero Michael. (1995). Handbook of English Language Proficiency Tests. http://www.ncela.gwu.edu/files/rcd/BE020503/Handbook_of_English.pdf (accessed 15/10/ 2012).

[25] Wille R.Jessica. (May 2006). Measuring the Academic Achievement and English Language Proficiency of students at the Secondary Level. http://www2.uwstout.edu/content/lib/thesis/2006/2006willej.pdf (accessed 05/10/2012).

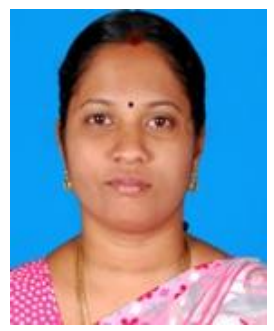

H. Jeraltin Vency, is a PhD Scholar at the Department of Educational Technology, Bharathidasan University, Tiruchirappalli, TamilNadu- 620023, India. She is currently working in the area of CLIL (Content and Language Integrated Learning) as her doctoral research. Her areas of interest are English Language Teaching and Educational Technology.

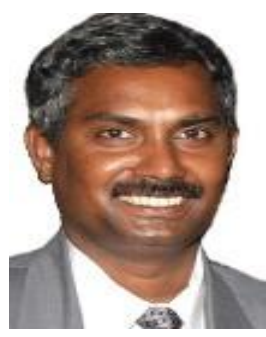

E. Ramganesh is a Professor at the Department of Educational Technology, Bharathidasan University, Tiruchirappalli, India. He has 20 years of research experience guiding M.Ed., M.Phil. \& Ph. D. Scholars in Education. His areas of interest are Educational Technology, Educational Psychology and Research Methodology.

He is serving as a reviewer of British Journal of Educational Technology, U.K. He has published more than 50 articles in reputed journals.

Dr. E. Ramganesh is a member in Board of Studies, Academic Council and Governing Council of different Universities in India. He is also the recipient of a prestigious award by the National Council of Educational Research and Training, India. He has been a project partner of SIM school project by Melinda Gates Foundation. He has also completed two Major research projects by National Funding Agencies, India. He has published more than 50 articles in reputed journals. 